\title{
Technology Readiness, Learning Goals, and eLearning: Searching for Synergy
}

\author{
Bo van der Rhee \\ David Eccles School of Business, University of Utah, 1645 E. Campus Center Drive, \\ Salt Lake City, UT 84112, e-mail: pmgtbr@business.utah.edu \\ Rohit Verma \\ Service Operations Management, School of Hotel Administration, Cornell University, Ithaca, \\ NY 14850, e-mail: rv54@cornell.edu \\ Gerhard R. Plaschka \\ Kellstadt Graduate School of Business, DePaul University, 1 East Jackson Blvd., Chicago, IL \\ 60604, e-mail: gplaschka@allgrp.com \\ Jill R. Kickul \\ Thomas C. Page Center for Entrepreneurship, Richard T. Farmer School of Business, Miami \\ University, 218 Upham, Oxford, $\mathrm{OH}$ 45056, e-mail: kickuljr@muohio.edu \\ More and more business schools are offering classes online or classes using a mix \\ of face-to-face and online elements. In this article, we focus on how technology \\ readiness and learning-goal orientation influence students' preference toward these \\ mixed classes. We conducted a large-scale survey to determine whether students who \\ are technology ready would place higher utility on enrolling in mixed classes and/or \\ whether there exists a participation bias such that students with low learning-goal \\ orientation place higher utility on enrolling in mixed classes. We found that overall \\ students who are more technology ready do place higher utility on enrolling in mixed \\ classes, but that learning goal orientation does not influence this decision. We conclude \\ with implications and recommendations for business schools that are interested in \\ offering mixed classes.
}

\section{Introduction}

More and more business schools offer eLearning opportunities: the U.S. News (Boser, 2004) reports that enrollment has increased by almost $20 \%$ in 2004 and $11 \%$ of postsecondary students will take at least one course online. According to CNN, eLearning has skyrocketed in popularity in recent years (Botelho, 2004) and Eduventures (www.eduventures.com), a Boston- 
based educational research firm, predicts that the eLearning market will grow more than $38 \%$, taking in $\$ 5.1$ billion. Over $90 \%$ of public colleges offer at least one course online and over thirty thousand graduate students were enrolled in online business degrees in the United States as of fall 2003. Even publicly traded for-profit educational operators are making substantial investments into online programming, such as Corporate Career Education with its American Intercontinental Online University. The boom in eLearning is likely to continue, especially with Congress considering removing the last obstacle preventing online students from qualifying for the same federal financial aid dollars as students at traditional universities.

In this article, we are interested in assessing the interaction between a students' technology readiness and learning-goal orientation on his/her preferences for enrolling in courses which include online instructional elements. In order to do so, we conducted a largescale survey among MBA students at two different universities in the United States. Because these "traditional" universities predominantly offer face-to-face classes, we are confronted with a potential selection bias. That is, if students actually prefer online classes, then they would enroll at a university which offers predominately such program offerings. As discussed later in this article, our data support the selection bias argument as our respondents predominately place the lowest utility on "pure online class offerings." The data also indicate that students with different levels of technology readiness and learning-goal orientation show different preferences for pure face-to-face classes when compared with mixed face-to-face and online course offerings. Before proceeding further, we define eLearning, technology readiness, and learning-goal orientation.

\section{elearning}

The term eLearning refers to using the Internet as a communications medium such that the instructor and the students can be separated by physical distance (Cooper, 1999). eLearning expands the learning opportunities of students who are time limited, live in remote communities, and/or have work or family commitments or other barriers that prevent them from attending a traditional classroom learning environment. Common elearning tools include discussion boards, e-mail, chat rooms, video streaming, document transfer, and other technologies to facilitate the educational process. The two market leaders which provide online course management software programs are WebCT and Blackboard and, like most other online course systems, they provide the instructor the ability to place information, readings, and other learning material for student use within the course that can be downloaded from the course server. These programs create a just-in-time learning environment where the student can access the material at their convenience and during a time that enhances their learning progress.

\section{Technology Readiness}

The term technology readiness, as introduced by Parasuraman and Colby (2001), describes the behavior process behind the adoption of technological products and services. 
Technology readiness can be broken up into four main constructs, two of which are positive: Optimism and Innovativeness, while the other two deal with concerns users might have: Discomfort and Insecurity. To determine a person's Technology Readiness Index (TRI) he or she would have to answer a number of questions, each related to one of these constructs. The questions can be found in Appendix $A$ and are discussed more in detail later.

\section{$\underline{\text { Learning-Goal Orientation }}$}

An individual with a high learning-goal orientation attempts to prove one's competency through the acquisition of new skills and knowledge for the sake of learning and to demonstrate mastery of a situation. We asked the students 10 questions on a five-point scale (from strongly agree to strongly disagree), tested and validated by Button, Mathieu, and Zajac (1996) (see Appendix B for the 10 questions).

The remaining sections of this article are organized as follows: in the next section, we build our hypotheses, after which we move on to the data and methods in the next section. The results are shown in the next section, and we draw our conclusions, offer recommendations, and discuss future research topics and limitations in the last section.

\section{Hypothesis Building}

\section{$\underline{T R I}$ and Preferences for Classes Offering Online Elements}

Parasuraman and Colby (2001) reveal in their study that there are five different types of technology-ready personalities. The group that is most ready for tackling new technologies is dubbed as explorers, who have the highest TRI. A person in this group is most optimistic about technology, shows the highest level of innovativeness, and is the least uncomfortable and least insecure with new technologies. Members of this group are also more likely to be students, which is of particular interest in the current study. Because technology plays such an important role in the online learning experience, we believe that a necessary, though not sufficient, condition for placing higher utility on registering for a class offering online elements is a high TRI. We therefore hypothesize a positive relationship between a student's TRI and the utility for classes offering online elements.

Hypothesis 1: A student's TRI has a positive relationship with his or her utility for enrolling in a class offering online elements.

More specifically, we expect that the four underlying constructs will have a positive (negative) effect on the utility for enrolling in a class offering online elements:

Hypothesis 1A: A student's optimism has a positive relationship with his or her utility for enrolling in a class offering online elements.

Hypothesis 1B: A student's innovativeness has a positive relationship with his or her utility for enrolling in a class offering online elements. 
Hypothesis 1C: A student's discomfort has a negative relationship with his or her utility for enrolling in a class offering online elements.

Hypothesis 1D: A student's insecurity has a negative relationship with his or her utility for enrolling in a class offering online elements.

Learning-Goal Orientation and Preferences for Classes Offering Online Elements

Several studies have examined the relationship between goal orientation in the acquisition of knowledge both in the classroom and in training programs (Burley, Turner, \& Vitulli, 1999; Johnson, Beauregard, Hoover, \& Schmidt, 2000; Kozlowski et al., 2001; Vande Walle, Cron, \& Slocum, 2001). According to Koestner and Zuckerman (1994), students with high learning-goal orientation employ a wider variety of learning strategies, knowledge exploration, and increased application of metacognitive knowledge. Given these characteristics, a traditional classroom setting which includes interaction with the professor and other students, active discussion and debate, as well as the use of a variety of learning techniques may be more attractive to a student with a higher learning-goal orientation.

Students with high learning-goal orientation are also found to be more flexible with change, persistent when confronted with difficult or new tasks, and are affected less by failure (Kozlowski et al., 2001). On the other hand, distance learning students have consistently higher dropout rates compared to traditional courses, indicating academic nonsuccess (Phipps \& Merisotis, 1999; Ridley \& Sammour, 1996), thus indicating a negative relationship.

Finally, according to the Wall Street Journal (Hayward, 2004) a majority of online students believe that "distance [eLearning] courses are not for slackers." However, while Gibson (1996) claimed that it is critical for distance-learning students to be more focused, better time managers, and to be able to work both individually and in teams, Wang, Kanfar, Hinn, and Arvan (2001) actually found that students who enrolled in an online class do not show higher levels of internal motivation, self-discipline, or better time management skills. In fact, the only relationships found are in the opposite direction, once again indicating a negative relationship between learning-goal orientation and preferences for classes with distancelearning elements.

Thus, the past research seems to suggest that, even though a more disciplined mind is needed for online classes, students who actually enroll in these classes tend to be relatively low on the learning-goal scale.

Hypothesis 2: A student's learning-goal orientation has a negative relationship with his or her utility for enrolling in a class offering online elements.

\section{Data and Method}

$\underline{\text { Data }}$

Empirical data for this study were collected from MBA students enrolled at two different 
universities. The universities are located in the United States, one in the Midwest and the other in the West. One university is located in a very large metropolitan region while the other is located in a mid-size city (population approximately 1.25 million). The first university is a private institution while the second university is a flagship public university within the state. Based on peer assessments of the two institutions by agencies, such as U.S. News, Kaplan, and Princeton Review, both universities have an excellent reputation for teaching and offer traditional programming (e.g., classes are predominately face-to-face, as opposed to being online universities).

Approximately 1,000MBAstudents randomly selected at the two universities received an e-mail from us with an invitation to join the research project. After the initial e-mail, each respondent was reminded twice within the next 10 days to complete the survey. In addition, each respondent's name was entered in a raffle for winning attractive prizes (10 Personal Digital Assistants). Finally, of the 940 potential respondents, 717 MBA students completed the survey in the three main areas of interest in this study (eLearning, technology readiness, and learning-goal orientation), resulting in a response rate of $76 \%$. However, only 643 respondents completed all sections of the survey and are subsequently used in our final analyses.

\section{Survey Overview}

The survey consisted of five sections. The first and last sections were dedicated to general respondent demographics: the first dealt with university experiences, such as the current enrollment, major, and number and types of courses taken, while the last dealt with more general demographics, such as age, gender, work experience, and current employment status. A preliminary look at the data revealed that almost twice as many males answered the survey as females (413 versus 232; 72 of the respondents did not answer this question), that $80 \%$ is 33 years of age or younger, and that we are dealing with a reasonably intelligent group of students: the average (self-reported) GPA of the 618 respondents who filled out the question was 3.57 (SD .30), with 90\% scoring an average GPA over a 3.0 and 56\% scoring over a 3.5 .

\section{eLearning Choice Sets}

The second section of the survey consisted of a choice analysis survey in which the students had to choose in eight three-choice sets (two different class offerings and a "neither" option) which type of class they preferred to enroll in. Our approach, commonly known as probabilistic discrete choice analysis (DCA) has been used to model choice processes of decision makers in a variety of academic disciplines, including marketing, operations management, transportation, urban planning, hospitality, and natural resource economics (e.g., Louviere \& Timmermans, 1990; Verma, Thompson, \& Louviere, 1999; Verma \& Plaschka, 2005). Rather than repeating what has already been detailed in various publications, here we only briefly describe the DCA method.

Discrete choice experiments involve careful design of profiles (a specific service) and choice sets (a number of services) in which two or more service alternatives are offered to 
decision makers and they are asked to evaluate the options and choose one (or none). In our case, each student was presented with two class offerings and the option to not enroll in either class. The design of the experiment is under the control of the researcher, and consequently, the decision makers' choices (dependent variable) are a function of the attributes of each alternative, personal characteristics of the respondents, and unobserved effects captured by the random component (e.g., unobserved heterogeneity or omitted factors). For a detailed theoretical and statistical background of DCA, see Ben-Akiva and Lerman (1991) and McFadden (1986).

DCA applications based on choice experiments typically involve the following steps: (a) identification of attributes, (b) specification of attribute levels, (c) experimental design, (d) presentation of alternatives to respondents, and (e) estimation of the choice model. Although design of choice experiments and estimation of multinomial logit (MNL) models requires sophisticated training and skills, implementing the estimated model(s) in spreadsheet-based decision support systems is fairly easy. Hence, DCA is very useful for practicing managers and is used here to explore the student's preferences for attributes of classes offering online elements.

The first stage in the design of our DCA study involved identification of relevant online course attributes and their levels. As recommended by Verma et al. (1999) we collected indepth qualitative data from various university administrators, educators, and students and requested that they suggest online course attributes and levels. Based on responses from over 25 individuals, a review of existing online course offerings, an assessment of possible new course features, and a review of academic and practitioner literature, we selected attributes and levels to reflect the key online course drivers. We then presented the list of attributes to a group of approximately 10 faculty members, administrators, and students in two different brainstorming sessions. Such an elaborate procedure for selecting course attributes and levels prior to conducting the DCA study is necessary to avoid missing potentially important attributes and also to restrict the experimental factors from exploding to a very large number (Verma et al., 1999). Table 1 lists the final set of attributes, their number of levels, and their classification mapped onto three conceptual factors identified during the qualitative research phase. The numbers in the brackets in Table 1 show the number of levels associated with each attribute.

\begin{tabular}{|c|c|c|}
\hline Core & Online & Support \\
\hline Tuition [4] & $\begin{array}{l}\text { Real-time online } \\
\text { collaboration [2] }\end{array}$ & Technical support [4] \\
\hline Face-to-face instruction [3] & Course Web site structure [2] & $\begin{array}{l}\text { In classroom high speed } \\
\text { network access [4] }\end{array}$ \\
\hline $\begin{array}{l}\text { Number of students } \\
\text { enrolled [4] }\end{array}$ & Web based technologies [4] & $\begin{array}{l}\text { Off-campus network } \\
\text { access [2] }\end{array}$ \\
\hline $\begin{array}{l}\text { Course duration and delivery } \\
\text { format [2] }\end{array}$ & $\begin{array}{l}\text { Ability to take course on self- } \\
\text { paced format [2] }\end{array}$ & \\
\hline
\end{tabular}

Table 1: eLearning choice exercise: Conceptual factors and attributes (numbers in brackets represent for each experimental attributes 
We labeled the first conceptual group of attributes identified during the qualitative research phase as "core" which includes basic and essential components of any course. Four attributes are includes in the core group-tuition/course, percent of time spent in face-to-face

instruction, number of students enrolled in class, and course duration and delivery format. The second of these attributes (percent of time spent in face-to-face instruction) is the attribute of particular interest to us in this study.

The second conceptual group of attributes is titled "online" and includes the following attributes - real-time online collaboration, course Web site structure, Web-based technologies used, and students' ability to take the course in a self-paced format. The third conceptual group titled "support" includes technical support, access to high-speed network in class, and the ability to access the campus network from off-campus locations. Thus, a total of 11 attributes with two to four levels each were identified as experimental variables for the course selection choice exercise.

Next we used a fractional factorial design that simultaneously created both the eLearning profiles as well as the choice sets into which to place them (Verma et al., 1999). We used a $2^{5} 3^{1} 4^{5}$ orthogonal design, which results in 128 questions. Each student was only presented with eight of these questions and so was asked to complete only 1/16 of the total orthogonal design. We were therefore unable to abstract information at the individual level, but because we were interested at an aggregate level, this did not present a problem, while having students answer 128 questions would have. To enhance the realism of the task, a fullprofile approach was used in presenting the choice sets (Green \& Srinivasan, 1990), that is, each profile shown to the respondents simultaneously described some combination of all the attributes. Next we randomly combined two profiles to generate choice sets. When combining profiles into choice sets, care was taken to ensure that there was minimum correlation between the two profiles within the same choice sets.

We pretested the online course selection choice task with approximately 25 randomly selected students (at the two different universities) to ensure ease and comprehension of the task, as well as to ensure reliable data collection methods. Average task completion time was 15 minutes and respondents did not report any difficulty in task comprehension. A screen-shot of a sample choice set is presented in Appendix C. Whenever necessary, attributes/levels for courses were hyperlinked with additional information presented in text format or with the aid of images. Because we discuss the method used to extract useful information from these choice sets in the section on results, we provide our results in that section rather than here.

\section{$\underline{\text { TRI Questions }}$}

Section three of the survey dealt with technology readiness and the 10 questions and scale developed by Parasuraman and Colby (2001) were used. In their book they describe how they reduced their initial 36 questions to four factors (or constructs) that explain technology readiness and from these four factors created an abbreviated TRI, which consists of only 10 
questions all rated on a 1 (strongly disagree) to 5 (strongly agree) scale. The four factors they identified are innovativeness, optimism, discomfort, and insecurity and to calculate the TRI we subtracted the negative attitudes toward technology (questions from the discomfort and insecurity factors) from the positive attitudes toward technology (questions from the innovativeness and optimism factors) as described in their research. For the 10 questions and the method to calculate the TRI, see Appendix A.

As expected, the TRI of the respondents (students) was generally higher than the average population: when we compared our respondents with those in Parasuraman and Colby (2001), we saw that only $8.2 \%$ had lower TRIs than 0 (compared to 59\%), and $41 \%$ scored lower than a 6 (compared to 86\%). We therefore divided our subjects into three groups as opposed to five: "Low Technology Readiness," with TRIs of up to 2 (14\%); "Medium Technology Readiness," with TRIs of between 2 and 8 (28\%); and "High Technology Readiness," with a TRI higher than 8 (48\%, 10\% left no data here). Further investigation also indicated that the student's GPA was uncorrelated with the TRI (correlation of $-.015, n s$ ). Thus, students with higher grades do not necessarily embrace new technology faster than students with lower grades or vice versa.

\section{$\underline{\text { Learning-Goal Orientation }}$}

In section four of the survey the students were asked to answer 10 questions related to their learning-goal orientation (Button et al., 1996). These questions (shown in Appendix B) were all coded positively and, as one might expect, the answers given by the 647 students who completely filled out these questions were generally more toward the strongly agree (5) than toward the strongly disagree (1) (average of the answers over all students was 4.46, SD .41), because this is a self-reported metric. We had to therefore be strict and we defined a student as having a low learning-goal orientation if his or her average over the 10 questions was lower than or equal to 4 , which resulted in 117 students (16\%). We defined student with a medium learning-goal orientation as those with an average higher than 4 but lower than or equal to 4.5 . In this group there were 215 students (30\%) and in the last group (students with high learninggoal orientation) there were 315 students (44\%; 10\% did not respond to these questions) who had self-reported averages higher than 4.5.

\section{Method}

In this section we will focus first on the most robust data set of the survey: the choice analysis. As discussed above for the eLearning concepts we used a classic choice set design approach. Subsequently, the congruency of the questions in the TRI section of the survey were checked using Cronbach's alpha to test for the constructs, as defined by Parasuraman and Colby (2001). We ran exploratory factor analysis (principle components) on the 10 TRI questions to check for the four factors as well as on the 10 learning-goal orientation questions, to see whether there were multiple factors there. After these preliminary tests, we focused on comparing the results obtained from running choice analyses on different subsets of the data as described in the results section. 


\section{Discrete Choice Analysis on the eLearning Section}

In order to understand student preferences for eLearning technologies, we need to consider the relative utilities that students attach to various features of courses (e.g., class size, online technologies used, technical support, etc.) that are available to them (Anderson, 1971; Louviere \&Woodworth, 1983). When faced with such a choice task, students are likely to use course features that they are already familiar with and also new features that are made available to them (Lynch, Marmorstein, \& Weigold, 1988). Therefore, to understand choice drivers for elearning features, we need to assess how students make trade-offs between prior feature knowledge acquired through past experience (e.g., traditional course features) and new features, that is, online-only course features.

We used the LIMDEP program by econometric software (www.limdep.com) to estimate MNL choice models for all respondents using a maximum likelihood estimation technique. The MNL model is expressed as

$$
\text { (1) }\left(P_{j} \mid C_{n}\right)=\frac{e^{V j \mu}}{\sum_{k=1}^{n} e^{V k \mu}}
$$

where $V_{j}$ represents the systematic component of utility $\left(U_{j}\right)$ of a choice alternative $j$ (BenAkiva \& Lerman, 1991). The model assumes that the utilities $\left(U_{j}\right)$ comprise a systematic component $\left(V_{j}\right)$, which can be estimated, and random error $(\varepsilon)$, which is independent and identically distributed according to a Gumbel distribution with a scale parameter $\mu$. $P_{j} \mid C_{n}$ represents the probability of selecting an alternative and therefore the expected market share. Representing a service as a bundle of its attributes, and by assuming an additive utility function, an alternative's systematic utility can be calculated as

$$
\text { (2) } V_{j}=\sum_{a \in A} \beta_{a} X_{a j} \text {, }
$$

where $\beta_{a}$ is the relative utility (part-worth utility) associated with attribute $a$.

Rather than going through the statistical details of the estimated choice models, in this article we describe the results in a more user-friendly format. At the same time we would like to assure the readers that the estimated models are statistically significant and meet all the established criteria established within the academic community.

\section{Exploring Technology Readiness and the Learning-Goal Orientation Constructs with Exploratory} Factor Analysis

Exploratory factor analysis was applied to a set of items (e.g., questions on a survey) to discover which items form coherent subsets relatively independent of each other. These items are than combined into factors (see Tabachnick \& Fidell, 2001).

When we performed a factor analysis on the 10 questions on the TRI with our data, using the general eigenvalue cutoff of 1.0, the 10 questions resulted in only three factors. Upon closer inspection, one of the three factors included both the discomfort and innovativeness 
questions and the eigenvalue for the fourth factor was .87, a value very close to the generally accepted cutoff of 1.0. Because an eigenvalue cutoff should be chosen such that the results provide the best trade-off between parsimony and managerial usefulness, other cutoff values have been used in the past (see, e.g., Rust, Lemon, \& Valarie, 2004 for a cutoff value of .5); we could choose a cutoff of .85 , in which case the resulting four factors not only contained exactly the questions that Parasuraman and Colby (2001) proposed (see Table 2), there were also no cross-loadings greater than .30 (the maximum cross-loading is .26).

\begin{tabular}{lcccc}
\hline & \multicolumn{3}{c}{ Component } \\
\cline { 2 - 5 } & 1 & 2 & 3 & 4 \\
\hline Optimism 1 & .62 & & \\
Optimism 2 & .74 & & \\
Optimism 3 & .80 & .60 & .76 & .79 \\
Discomfort 1 & & .79 & & .74 \\
Discomfort 2 & & & \\
Innovativeness 1 & & & .74 \\
Innovativeness 2 & & & \\
Insecurity 1 & & & \\
Insecurity 2 & & & \\
Insecurity 3 & & & \\
Extraction method: Principal Component Analysis. & \\
Rotation method: Varimax with Kaiser Normalization. & \\
\hline
\end{tabular}

Note: loadings $<.30$ are not shown and the numbers of the questions coincide with Appendix A.

Table 2: Exploratory factor analysis on the technology readiness index questions.

For the learning-goal orientation the results were rather simple as we ended up with only one factor: the first eigenvalue was 4.50 , the second was 1.07 , followed by eigenvalues below .75. The split into two factors did not increase parsimony or managerial usefulness, so we continued under the assumptions that we were dealing with a composite scale.

\section{Results}

Before we discuss any of the different choice models, it is insightful to briefly discuss the results of the complete model (all 643 students). First, the relative importances of the different attributes are shown in Figure 1. Some observations can be made at first glance: students put the highest relative importance on price, and within the price attribute they preferred lower tuition, which could be expected. Noticeably, the second most important attribute was the format: face-to-face, mixed, or online. Overall, students preferred face-to-face classes and 
mixed classes to pure online classes, as they have already chosen to enroll at a traditional university, as can be seen in Figure 2.

The class size was next in the students' importance, and they preferred smaller class sizes. After the top three most important attributes of a class, there was a huge drop to other issues, such as technical support (where they preferred more over less).

Apparently the face time attribute is a very important attribute, and overall, the students we surveyed did not prefer to enroll in exclusively online classes, as we expected from the preselection bias. But how do the students with different TRIs and learning-goal orientation differ in their utilities for pure face-to-face versus mixed classes? This question can be answered by comparing the different choice models. In order to be able to draw any conclusions that could lead us to reject or find support for our hypotheses, we needed to run

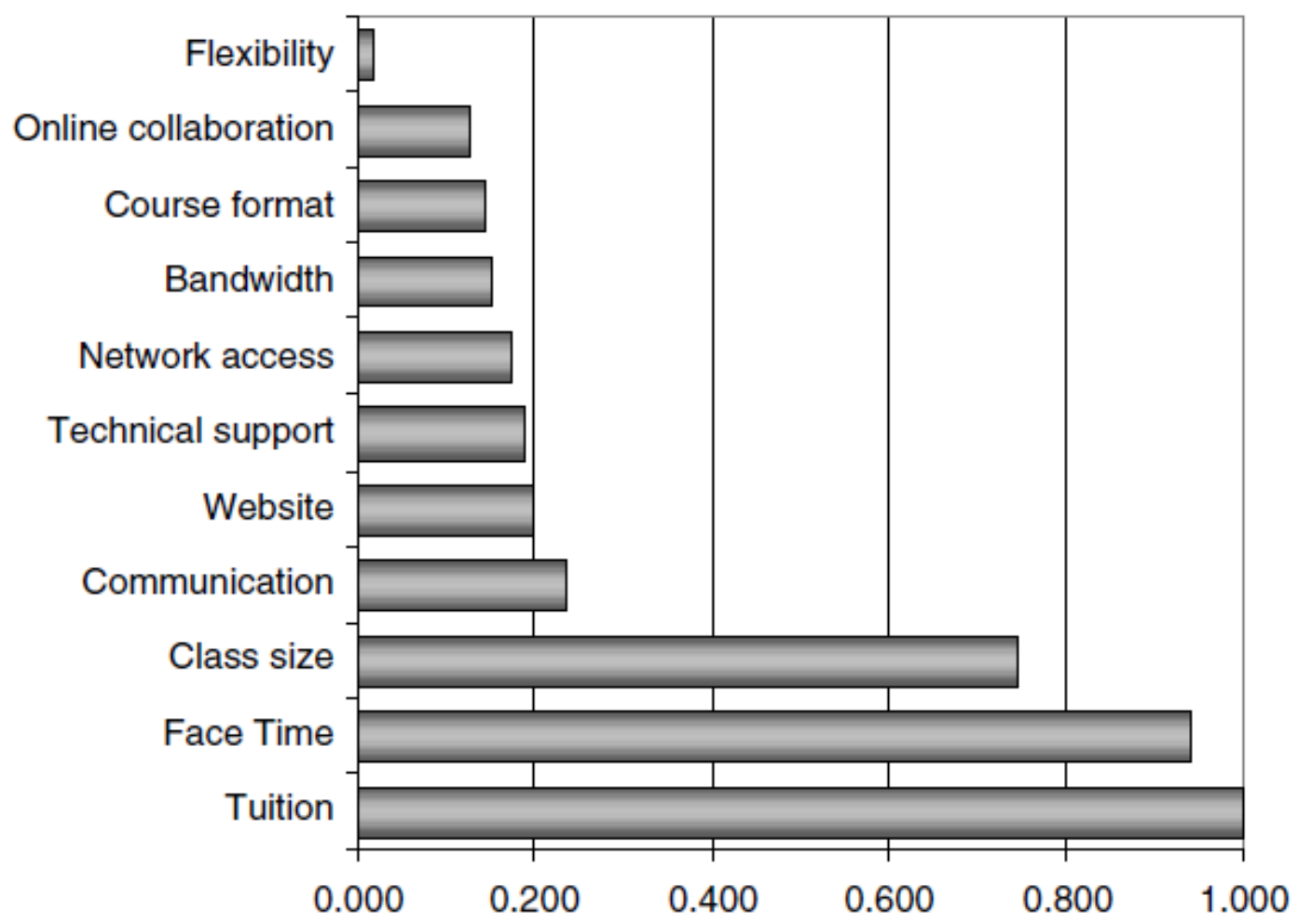

Figure 1: Relative importance of the difference attributes

the choice model for different groups of students. For example, to be able to show a possible positive effect of the TRI on the willingness to enroll in classes offering online elements, we separated the students into three groups: the students with a relatively low TRI, those with a medium TRI, and those with a high TRI as mentioned above. We then compared the results from the different choice models for these different groups of students and checked whether students with a lower TRI indeed had lower utilities for enrolling in a class that offers online elements than those students with a higher TRI (Hypothesis 1). Consequently, we split up the 
students along their four constructs into low, medium, and high as well to check Hypotheses $1 \mathrm{~A}$ through 1D. The same procedure was used to validate Hypothesis 2 where we split up the students into three groups according to their learning-goal orientation, as we discussed previously.

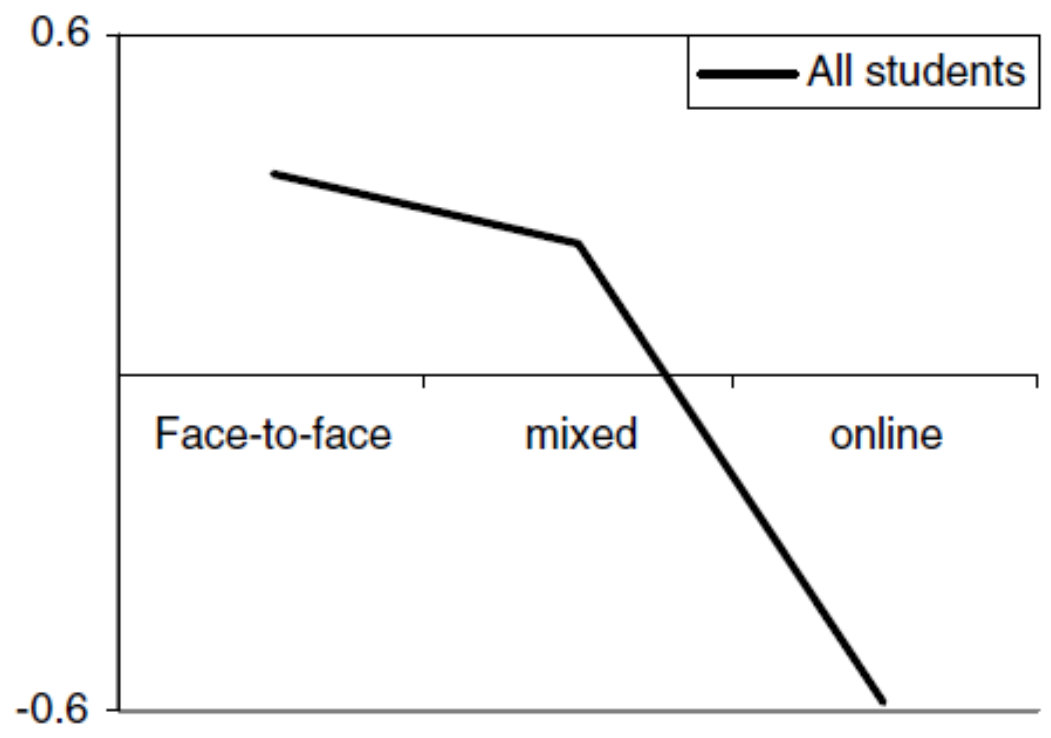

Figure 1: All students' preferences for the three levels of the face attributes

Because we needed to run the whole choice model (we cannot just focus on the type of class, as it is part of a choice-based conjoint analysis), the data also revealed some interesting insights in the other variables. We discuss these findings briefly in the final section and we leave the implications of these insights up to future research.

\begin{tabular}{|c|c|c|c|c|}
\hline Attribute & Level: & TRIs: & Low & High \\
\hline \multirow[t]{2}{*}{ Face time } & Face-to-face & & .4777 & .1654 \\
\hline & Mixed & & .0446 & .2967 \\
\hline
\end{tabular}

Note: The highest values are in bold.

Table 3: Standardized utilities for the face time attributes.

\section{Comparison of Technology Readiness Choice Sets}

As mentioned, in order to find support for our hypothesis we split up the students into three groups with respect to their TRIs. After separating the students into their respective groups, we ran the model three times (for students with a low, medium, and high TRI). Students with higher TRIs preferred face-to-face and mixed classes to online classes, and they disliked the online classes less than the students with low TRIs. As mentioned, we leave the evaluation of the online level to future studies. 
Table 3 and Figure $3^{1}$ reveal that students with the highest TRIs placed a higher utility on mixed classes than on pure face-to-face classes ( $t$ statistic $=38.9$, df 582, $p$ value $\ll .001$ ), whereas the students with the lowest TRIs actually showed a reverse relationship: they placed a higher utility at the pure face-to-face class ( $t$ statistic $=50.6$, df 192, $p$ value $\ll .001$ ). Also, the students with the highest TRIs placed significantly higher utility at the mixed class than the students with the lowest TRIs ( $t$ statistic $=45.2, \mathrm{df} 387, p$ value $\ll .001$ ), while these students placed significantly higher utility at the face-to-face class than the students with the highest TRIs ( $t$ statistic $=80.2$, df 387, $p$ value $\ll 0.001$ ). We therefore conclude that we can support our first hypothesis.

\section{Comparison of Optimism Choice Sets}

We separated the students with respect to different levels of optimism in a similar way as we did for the TRIs. We created three groups representing students with low (lower than or equal to an average score of 4 , on the three questions dealing with optimism; 252 students), medium (between 4 and 4.5 on average; 143 students) and high (higher than 4.5 on average; 248 students) levels of optimism.

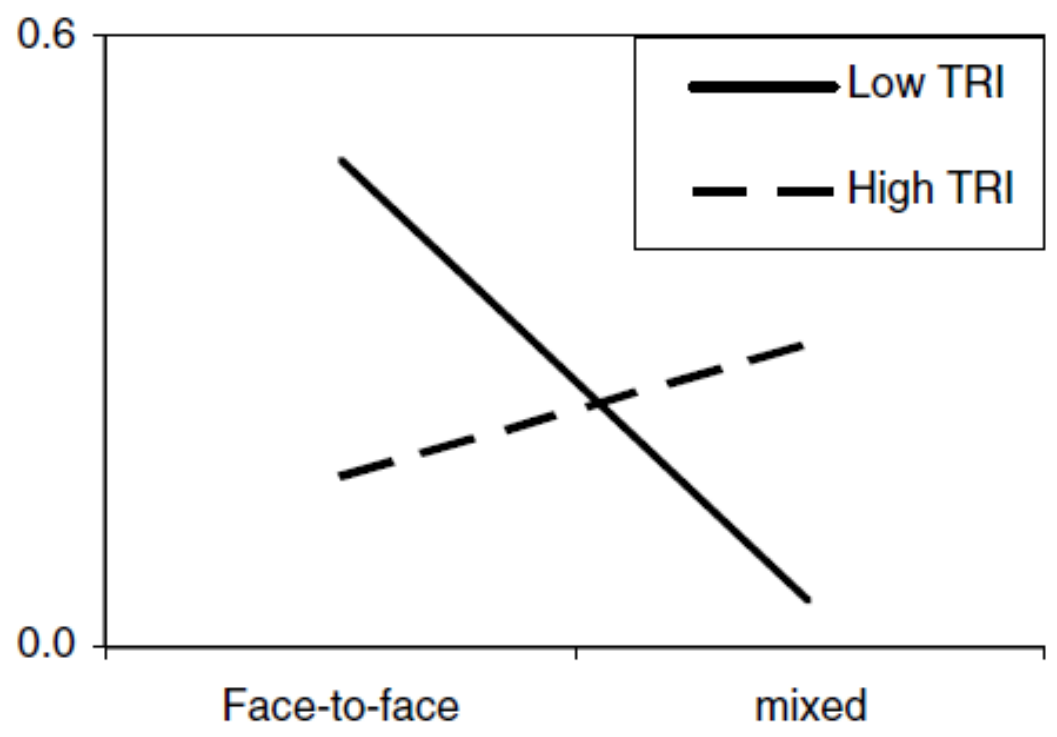

Figure 3: Standardized utilities for the face time attributes with students separated by technology readiness index.

The results concerning the face time attribute were even more pronounced for the optimism construct of TRI than for the TRI itself and are therefore probably the driver of the results for the TRI. The most optimistic students placed higher utility on the mixed classes over the pure face-to-face classes ( $t$ statistic $=38.9$, df 582, $p$ value $\ll .001$ ), while the least optimistic students placed higher utility on the face-to-face classes ( $t$ statistic $=50.6, \mathrm{df} 192, p$ value $\ll 0.001$ ) as can be seen in Table 4 and Figure 4 . Also, the optimistic students placed far 
higher utility on the mixed class than the least optimistic students ( $t$ statistic $=110.5, \mathrm{df} 498, p$ value $\ll .001)$, while these students placed higher utility on the face-to-face class than the most optimistic students ( $t$ statistic $=52.5, \mathrm{df} 498, p$ value $\ll .001$ ). Thus we found evidence to support Hypothesis $1 \mathrm{~A}$.

\section{Comparison of Innovativeness Choice Sets}

Here we separated the three groups by the following cutoffs: average score less than or equal to 3, or neutral, ("low innovativeness," 237 students), between 3 and 4 ("medium innovativeness," 280 students), and higher than 4 ("high innovativeness," 126 students).

The results concerning the online classes were less pronounced for the innovativeness construct than for the optimism construct (see Table 5 and Figure 5): although the most innovative students placed higher utility on the mixed classes than on the pure face-to-face classes ( $t$ statistic $=.38, \mathrm{df} 250, p$ value $n s$ ) and higher utility on the mixed class than the least

\begin{tabular}{|c|c|c|c|c|}
\hline Attribute & Level: & Optimism: & Low & High \\
\hline \multirow[t]{2}{*}{ Face time } & Face-to-face & & .4400 & .0679 \\
\hline & Mixed & & 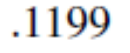 & 3781 \\
\hline
\end{tabular}

Note: The highest values are in bold.

Table 4: Standardized utilities for the face time attributes.

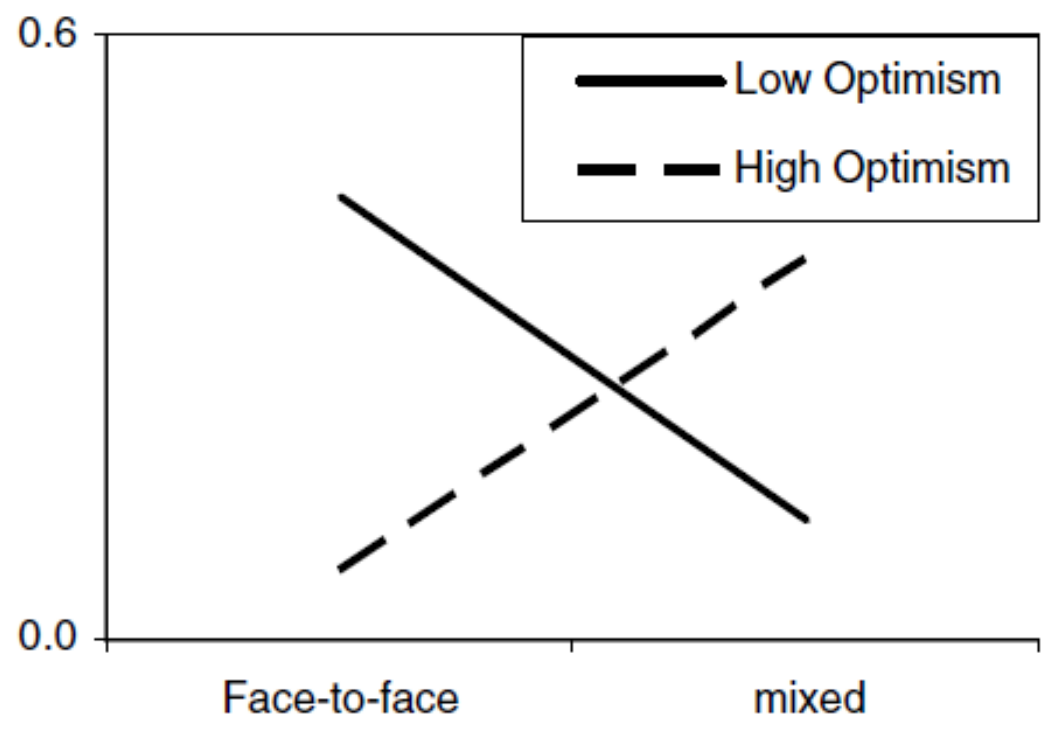

Figure 4: Standardized utilities for the face time attributes with students separated by optimism. 


\begin{tabular}{|c|c|c|c|c|}
\hline Attribute & Level: & Innovativeness: & Low & High \\
\hline \multirow[t]{2}{*}{ Face time } & Face-to-face & & .4106 & .2369 \\
\hline & Mixed & & .1491 & .2405 \\
\hline
\end{tabular}

Note: The highest values are in bold.

Table 5: Standardized utilities for the face time attributes

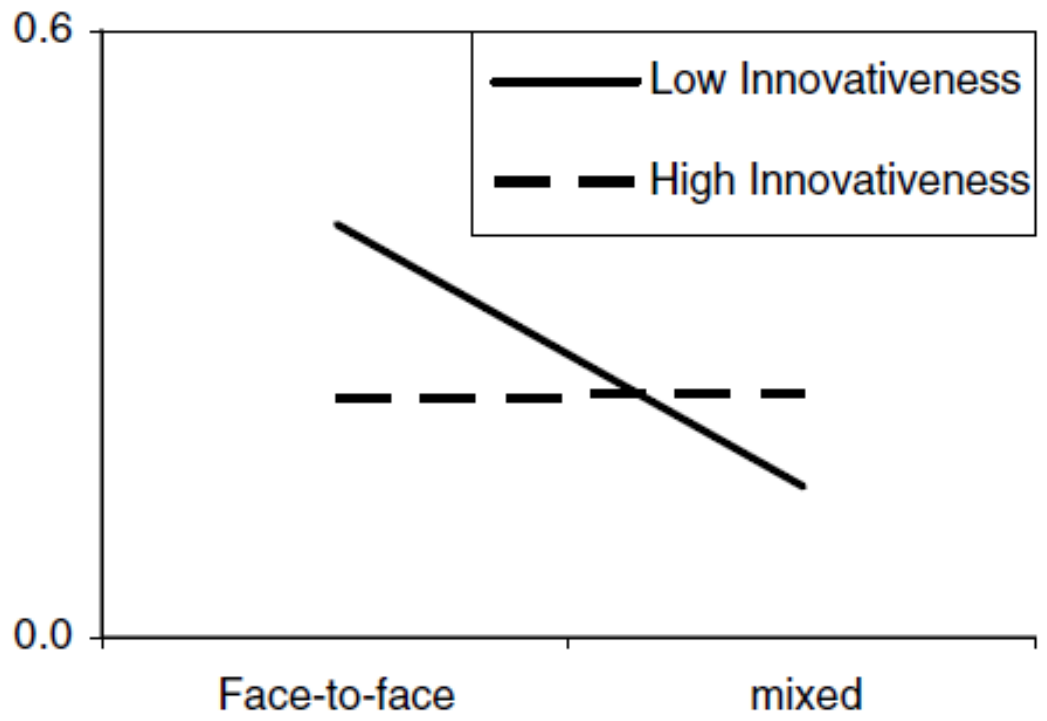

Figure 5: Standardized utilities for the face tome attributes with students separated by innovativeness.

\begin{tabular}{|c|c|c|c|c|}
\hline Attribute & Level: & Discomfort: & Low & High \\
\hline \multirow[t]{2}{*}{ Face Time } & Face-to-face & & .3148 & .4521 \\
\hline & Mixed & & .2586 & .0959 \\
\hline
\end{tabular}

Note: The highest values are in bold.

Table 6: Standardized utilities for the face time attributes.

innovative students ( $t$ statistic $=2.8, \mathrm{df} 361, p$ value $<.01$ ) the differences were either nonsignificant or less so. The students with the lowest innovativeness did place higher utility on the face-to-face class than on the mixed class though ( $t$ statistic $=74.3$, df $472, p$ value $\ll .001$ ) and they also placed higher utility on the face-to-face class than the students with the highest innovativeness ( $t$ statistic $=63.8, \mathrm{df} 361, p$ value $\ll .001$ ). The conclusion here is thus that we found partial support for Hypothesis 1B. 


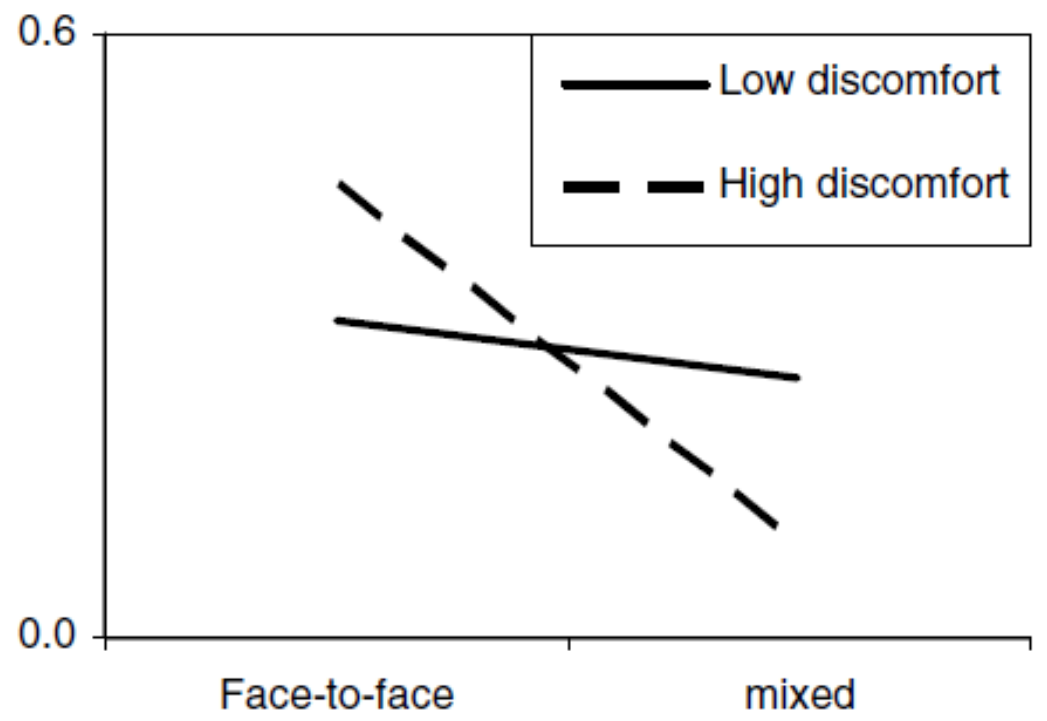

Figure 6: Standardized utilities for the face time attributes with students separated by discomfort.

\section{Comparison of Discomfort Choice Sets}

The cutoffs for the three groups here were: average score less than or equal to 1.5 ("low discomfort," 197 students), between 1.5 and 2.5 ("medium discomfort," 300 students), and higher than 2.5 ("high discomfort," 146 students). Notice that for the discomfort construct a lower score would indicate a higher TRI, because the answers to these questions (as well as to the next construct of insecurity) were subtracted from the answers provided to the previous two (positive) constructs. The cutoffs were therefore on the lower end of the scale, because we are still dealing with students who are in general technology savvy.

The results for the discomfort construct were less convincing still than in the previous cases as can be seen in Figure 6 and Table 6 . Here the students with the highest discomfort levels did place higher utility on the face-to-face class format than the students with the lowest levels of discomfort ( $t$ statistic $=30.5$, df 341, $p$ value $\ll .001$ ) and vice versa for the mixed class where the least discomforted students placed a higher utility ( $t$ statistic $=32.2, \mathrm{df} 341, p$ value $\ll .001)$, but because both the low and the high discomfort groups placed the highest utility on

\begin{tabular}{|c|c|c|c|c|}
\hline Attribute & Level: & Insecurity: & Low & High \\
\hline \multirow[t]{2}{*}{ Face Time } & Face-to-face & & .2013 & .3077 \\
\hline & Mixed & & .2856 & .1776 \\
\hline
\end{tabular}

Note: The highest values are in bold.

Table 7. Standardized utilities for the face time attributes. 
the pure face-to-face class (both at a $p$ value $\ll .001$ ), we conclude that Hypothesis $1 \mathrm{C}$ is also only partially supported.

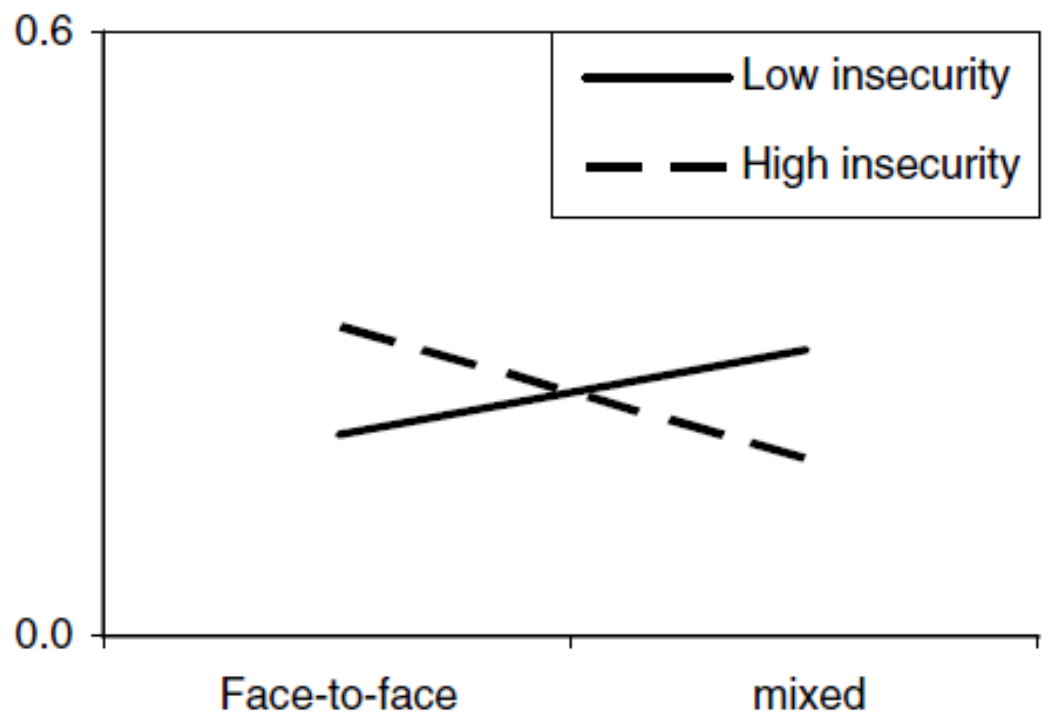

Figure 7: Standardized utilities for the face time attributes with students separated by insecurity.

\section{Comparison of Insecurity Choice Sets}

Finally we looked at insecurity, where we created the three groups using the following cutoffs: average score less than or equal to 2 ("low insecurity," 236 students), between 2 and 3 ("medium insecurity," 246 students), and higher than 3 ("high insecurity," 161 students). Just as with the previous construct (discomfort), we separated on the low end of the scale, because the insecurity construct is also negative (i.e., the answers to the questions for this construct were subtracted from the answers to the positive constructs).

Here the students did behave completely as hypothesized (see Table 7 and Figure 7): the students in the low insecurity group placed the highest utility on the mixed class, both when compared with the face-to-face class ( $t$ statistic $=20.5$, df $470, p$ value $\ll .001$ ), as when compared with the students with the highest levels of insecurity ( $t$ statistic $=32.4, \mathrm{df} 395, p$ value $\ll .001)$. Also, the most insecure students placed higher utility on the face-to-face class

\begin{tabular}{lllll}
\hline Attribute & Level: & Learning Goal: & Low & High \\
\hline Face Time & Face-to-face & $\mathbf{. 3 0 7 7}$ & $\mathbf{. 3 4 6 7}$ \\
& Mixed & .1776 & .2652 \\
\hline
\end{tabular}

Note: The highest values are in bold.

Table 8: Standardized utilities for the face time attributes. 


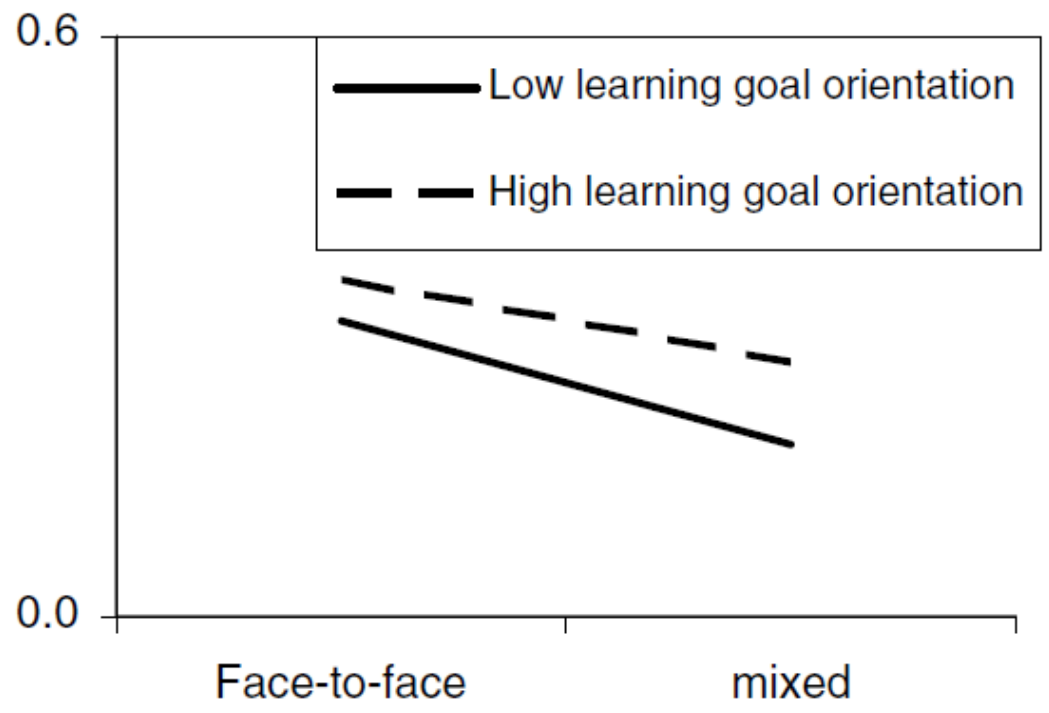

Figure 8: Standardized utilities for the face time attribute with students separated by learninggoal orientation.

format, both when compared with the mixed class ( $t$ statistic $=50.0$, df $320, p$ value $\ll .001$ ) and with the students who felt most secure with new technology ( $t$ statistic $=54.7, \mathrm{df} 395, p$ value $\ll .001)$. Thus we conclude that Hypothesis $1 \mathrm{D}$ is supported.

\section{Comparison of Learning-Goal Orientation Choice Sets}

In comparing the students with respect to their learning-goal orientation, we divided them into three groups with the following cutoffs: average score less than or equal to 4 ("low learning-goal orientation," 116 students), between 4 and 4.5 ("medium learning-goal orientation," 215 students), and higher than 4.5 ("high learning-goal orientation," 312 students). As discussed above, we had to be strict in separating them into these groups as it is a self-reported measure. When we look at the data (Table 8 and Figure 8 ), we see that there is no crossover effect as in all the previous cases. We therefore did not find support for Hypothesis 2, as both groups actually preferred the face-to-face class format ( $p$ values both $\ll .001$ ).

\section{Discussion and Future Research Issues}

The results uncovered in this study represent one of the first empirical insights that examine the preferences of graduate students with respect to eLearning (represented by the face time attribute) and other course attributes with technology readiness and learning-goal orientation. The results of our study yield information that may be useful in guiding future research as they address key factors essential to the adoption and effective integration of elearning strategies, initiatives, and opportunities for educational programs, courses, and pedagogy. 
In general we find support for our hypotheses on TRI: the overall hypothesis and two out of the four subhypotheses (Hypotheses 1A to 1D) were supported (the other two only partially) and we found that higher technology readiness does in fact lead to higher utilities for mixed classes, as opposed to lower technology readiness. Even though we did not find support for our second hypothesis, this actually presents some good news for the traditional academic profession. That is, if a business school or individual professor is interested in offering a class with online elements, there should be no reason to worry about attracting only students with low learning goals.

Looking at the total output (not just the class format) we can make some interesting observations on the other attributes which could be researched in the future. First, students with low learning-goal orientation have an all-or-nothing approach to the communication attribute in the sense that the access to all communication option (e-mails + discussion + Personal Digital Assistant access + audio/video) received the highest rating, whereas one step down, that is, all options except for the audio/video option, received the lowest rating. Alternatively, the students with high learning-goal orientation place the highest value on the latter option. Thus, if a business school would offer a mixed class without offering audio/video communication components, it would attract relatively more students with a high learning-goal orientation.

Second, students with a higher TRI and who were most innovative placed higher utility on having more technical support. At first this seemed counterintuitive, but then we realized that students who have a higher understanding and appreciation for technology (higher TRI) would like to be able to work with it more often and thus would appreciate technical support more often as well.

Finally, the most optimistic students and the most innovative students actually preferred sparse access throughout the classroom the most, over full wireless access in all classrooms. The reason for this observation might have something to do with the fact that the most optimistic students also might be the most realistic, but, as mentioned above, we leave implications of this finding to future research.

While among the few to study student preferences for elearning course features, our study has some limitations. First, the study is based on data collected from only two universities and hence has limited generalizability. Further research needs to be conducted that expands the scope of the findings to universities beyond the one that we studied. Second, while our results permit us to make generalizations about various student segments based on technology readiness and learning-goal orientation, our study is essentially a cross-sectional one. We need more research that tracks the same set of students as they evolve from low to high familiarity with eLearning course environments. This type of longitudinal panel research of choice behavior is enabled by using the Wharton Virtual Test Panel (see Lohse, Bellman, \& Johnson, 2000 for details). Fourth, we used a priori criteria for student segmentation. Future research needs to use latent class and other segmentation techniques to allow student segments to 
emerge from the data itself, thus accounting for heterogeneity that may exist between segments (Degeratu, Rangaswamy, \& Wu, 2000). Finally, our results apply only to current students and not the potential students who may (or may not) choose to attend traditional universities. However, despite the limitations, we believe that our results and conclusions add to existing scholarship on online learning environments and also enable university managers to create courses that best satisfy the needs of their students.

\section{References}

Anderson, N. H. (1971). Integration theory and attitude change. Psychological Review, 78, 171206.

Ben-Akiva, M., \& Lerman, S. R. (1991). Discrete choice analysis. Cambridge, MA: MIT Press.

Boser, U. (2004). Working on what works best. U.S. News, for the full article, go to http://www.usnews.com/usnews/edu/elearning/articles/03good.htm.

Botelho, G. (2004). Online schools clicking with students: Flexibility, technology key to elearning. CNN.com, for the full article, go to http://www.cnn.com/2004/EDUCATION/08/13/b2s.elearning/index.html.

Burley, R. C., Turner, L. A., \& Vitulli,W. F. (1999). The relationship between goal orientation and age among adolescents and adults. The Journal of Genetic Psychology, 160(1), 84-88.

Button, S. B., Mathieu, J. E., \& Zajac, D. M. (1996). Goal orientation in organizational research: A conceptual and empirical foundation. Organizational Behavior and Human Decision Processes, 67, 26-48.

Cooper, L. (1999). Anatomy of an on-line course. THE Journal, 26, 49. Retrieved May 25, 1999 from INFOTRAC SearchBank (Article \# A53929573).

Degeratu, A., Arvind, R., \& Jeremy, W. (2000). Consumer choice behavior in online and regular stores: The effects of brand name, price, and other search attributes. International Journal of Research in Marketing, 17, 55-78.

Green, P. E., \& Srinivasan, V. (1990). Conjoint analysis in marketing: New developments with implications for research and practice. Journal of Marketing, 54(October), 3-19.

Gibson, C. (1996). Toward an understanding of self-concept in distance education. American Journal of Distance Education, 10(1), 23-36.

Hayward, S. (2004). Going online for your MBA may mean showing up for class. The Wall Street Journal Online (September 22). For the full article, go to http://online.wsj.com/public/article/0,SB109398966309906191,00.html?mod=home inside today us. 
Johnson, D. S., Beauregard, R. S., Hoover, P. B., \& Schmidt, A. M. (2000). Goal orientation and task demand effects on motivation, affect, and performance. Journal of Applied Psychology, 83(5), 724-738.

Koestner, R., \& Zuckerman, M. (1994). Causality orientation, failure, and achievement. Journal of Personality, 62, 321-345.

Kozlowski, S. W., Gully, S. M., Brwon, K. G., Salas, E., Smith, E. M., \& Nason, E. R. (2001). Effects of training goals and goal orientation traits on multidimensional training outcomes and performance adaptability. Organizational Behavior and Human Decision Processes, 85(1), 1-31.

Lohse, G., Bellman, S., \& Johnson, E. J. (2000). Consumer buying behavior on the internet: Findings from panel data. Journal of Interactive Marketing, 14(1), 15-29.

Louviere, J. J., \& Timmermans, H. (1990). Stated preference and choice models applied to recreation research: A review. Leisure Science, 12, 9-32.

Louviere, J. J., \& Woodworth, G. (1983). Design and analysis of simulated consumer choice or allocation experiments: An approach based on aggregate data. Journal of Marketing Research, 20, 350-367.

Lynch, J. G., Marmorstein, H., \&Weigold, M. F. (1988). Choices from sets including remembered brands: Use of recalled attributes and prior overall evaluations. Journal of Consumer Research, 15, 169-184.

McFadden, D. (1986). The choice theory approach to market research. Marketing Science, 5(4), 275-297.

Parasuraman, A., \& Colby, C. L. (2001). Techno-ready marketing-how and why your customers adopt technology. New York. The Free Press.

Phipps, R., \& Merisotis, J. (1999). What's the difference? A review of contemporary research on the effectiveness of distance learning in higher education. Washington, DC: The Institute for Higher Education Policy.

Ridley, D. R., \& Sammour, H. Y. (1996). Viable alternative means of instructional delivery: Online courses as an alternative teaching method. College Student Journal, 30, 337-339.

Rust, R. T., Lemon, K. N.,\&Valarie, A. Z. (2004). Return on marketing: Using customers equity to focus marketing strategy. Journal of Marketing, 68(January), 109-127.

Tabachnick, G. B., \& Fidell, L. S. (2001). Using multivariate statistics (4th ed.). Boston: Allyn \& Bacon.

VandeWalle D., Cron, W. L., \& Slocum, J. W. (2001). The role of goal orientation following performance feedback. Journal of Applied Psychology, 86(4), 629-640. 
Verma, R., \& Plaschka, G. (2005, Fall). Predicting customer choices. MIT Sloan Management Review, 47(1), 7-10.

Verma, R., Thompson, G. M., \& Louviere, J. J. (1999). Configuring service operations based on customer needs and preferences. Journal of Service Research, 1(3), 262-274.

Wang, X. C., Kanfar, A., Hinn, D. M., \& Arvan, L. (2001, May). Stretching the boundaries: Using ALN to reach on-campus students during an off campus summer session. Journal of Asymmetric Learning Networks, 5(1), 1-20.

\section{Appendix A: The TRI Scale}

These are the 10 questions used in the survey to measure the TRI, the factor name is in parentheses after each question and was not shown to the participants:

1. I can usually figure out new hi-tech products and services without help from others. (Innovativeness 1)

2. New technology is often too complicated to be useful. (Discomfort 1)

3. I like the idea of doing business via computers because you are not limited to regular business hours. (Optimism 1)

4. When I get technical support from a provider of a high-tech product or service, I sometimes feel as if I am being taken advantage of by someone who knows more than I do. (Discomfort 2)

5. Technology gives people more control over their daily lives. (Optimism 2)

6. I do not consider it safe giving out credit card information over a computer. (Insecurity 1)

7. In general, I am among the first in my circle of friends to acquire new technology when it appears. (Innovativeness 2 )

8. I do not feel confident doing business with a place that can only be reached online. (Insecurity 2)

9. Technology makes me more efficient in my occupation. (Optimism 3)

10. If you provide information to a machine or over the internet, you can never be sure if it really gets to the right place. (Insecurity 3 )

Each question was answered on a Strongly Disagree (1) to Strongly Agree (5) scale. The TRI was calculated as follows: $(1+3+5+7+9)-(2+4+6+8+10)$.

\section{Appendix B: The Learning-Goal Orientation Scale}

These are the 10 questions used in the survey to measure the learning goal orientation:

1. The opportunity to do challenging work is important to me.

2. When I fail to complete a difficult task, I plan to try harder the next time I work on it.

3. I prefer to work on tasks that force me to learn new things.

4. The opportunity to learn new things is important to me. 
5. I do my best when I am working on a fairly difficult task.

6. I try hard to improve on my past performance.

7. The opportunity to extend the range of my abilities is important to me.

8. When I have difficulty solving a problem, I enjoy trying different approaches to see which one will work.

9. On most jobs, people can pretty much accomplish whatever they set out to accomplish.

10. Your performance on most tasks or jobs increases with the amount of effort you put into them.

Each question was answered on a Strongly Disagree (1) to Strongly Agree (5) scale. The learning goal orientation for a particular student was calculated by taking the average over all 10 questions.

\section{Appendix C: Sample Screen-shot of Course Selection Choice Exercise}

\begin{tabular}{|c|c|c|c|}
\hline Course Set \#2 & Course Format \#1 & Course Format \#2 & \\
\hline Tuition for one course & $10 \%$ LOWER than current tuition & SAME as current tuition & \\
\hline $\begin{array}{l}\text { Percent of class time spent on } \\
\text { "face-to-face" instruction }\end{array}$ & $\begin{array}{l}\text { Class time is MIXED between online \& face- } \\
\text { to-face instruction }\end{array}$ & $\begin{array}{l}\text { Class time is MIXED between online \& } \\
\text { face-to-face instruction }\end{array}$ & \\
\hline $\begin{array}{l}\text { Web-based technologies used in } \\
\text { the course }\end{array}$ & $\begin{array}{l}\text { Emails } \\
\text { Discussion forums } \\
\text { Chats/instant messaging and PDA access }\end{array}$ & $\begin{array}{l}\text { Emails } \\
\text { Discussion forums } \\
\text { Chats/instant messaging and PDA } \\
\text { access }\end{array}$ & \\
\hline "Real-time" online collaboration & No available & No available & \\
\hline Course web-site structure & $\begin{array}{l}\text { INTEGRATED \& INTERACTIVE course } \\
\text { management website (e.g. Blackboard) }\end{array}$ & $\begin{array}{l}\text { STATIC site primarily containing course } \\
\text { documents }\end{array}$ & \\
\hline Technical support & $\begin{array}{l}\text { Professionally managed support: 8AM-10PM } \\
\text { WEEKDAYS \& WEEKEND }\end{array}$ & $\begin{array}{l}\text { Professionally managed support: 8AM- } \\
\text { 5PM WEEKDAYS }\end{array}$ & \\
\hline $\begin{array}{l}\text { Access to high speed network in } \\
\text { classroom }\end{array}$ & $\begin{array}{l}\text { Network Access points SPARSELY located } \\
\text { throughout the classroom }\end{array}$ & $\begin{array}{l}\text { Network Access points SPARSELY } \\
\text { located throughout the classroom }\end{array}$ & \\
\hline $\begin{array}{l}\text { Off-campus access speed } \\
\text { requirement }\end{array}$ & $56 \mathrm{~K}$ telephone modem connection & $\begin{array}{l}\text { High Speed Internet (e.g. DSLCable } \\
\text { Modem/LAN) access required }\end{array}$ & \\
\hline $\begin{array}{l}\text { Course duration \& delivery } \\
\text { format }\end{array}$ & $\begin{array}{l}\text { STANDARD course ( } 3 \text { hrs/week for } 14 \\
\text { weeks) }\end{array}$ & $\begin{array}{l}\text { STANDARD course ( } 3 \mathrm{hrs} / \text { week for } 14 \\
\text { weeks) }\end{array}$ & \\
\hline $\begin{array}{l}\text { Ability to take course on a self- } \\
\text { paced format }\end{array}$ & $\begin{array}{l}\text { Yes (Must complete course requirements } \\
\text { within } 1 \text { calendar year) }\end{array}$ & No & \\
\hline $\begin{array}{l}\text { Average number of students } \\
\text { enrolled }\end{array}$ & Less than 30 students & 60 - 90 students & \\
\hline I will take this course & $c$ & 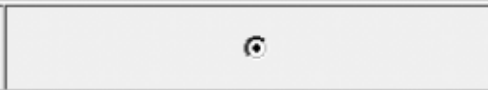 & $\begin{array}{l}\mathrm{C} \\
\text { Neither }\end{array}$ \\
\hline
\end{tabular}

Continue

\section{Authors Bios}

Bo van der Rhee is a PhD Candidate (ABD) in operations management at the David Eccles School of Business, University of Utah. His primary research interests are in innovations in technology management and new product development. He serves as a reviewer for Production and Operations Management, Decision Sciences, and European Journal of Operational Research. 
Rohit Verma is an associate professor of service operations management at the School of Hotel Administration, Cornell University. He is currently on leave from David Eccles School of Business, University of Utah, where he holds the position of George S. Eccles Professor of Management. His research has appeared in California Management Review, Cornell Quarterly, Decision Sciences, Journal of Operations Management, Journal of Product Innovation Management, Journal of Service Research, MIT Sloan Management Review, Production and Operations Management, and other journals. He serves as an associate editor of Journal of Operations Management and Decision Sciences, senior editor of Production and Operations Management, and editorial board member of Journal of Service Research and Cornell Quarterly. He also served as guest editor for five issues of Journal of Operations Management on topics related to effective management of service businesses.

Gerhard R. Plaschka is an associate professor in strategy and venture management in the Kellstadt Graduate School of Business at DePaul University, Chicago. He obtained his PhD at the Vienna University of Economics and Business Administration, Austria. His primary research interests are demand-side-based strategy issues within highly complex, emerging and mature industrial product and service markets. His collaboration with senior executives in Global 500 companies and distinguished researchers has enabled him to establish a distinctive demandside driven understanding of corporate strategy using choice modeling methods. He has published in MIT Sloan Management Review, California Management Review, Cornell Hotel and Restaurant Administration Quarterly, Decision Sciences, Entrepreneurship Theory and Practice, and Zeitschrift fuer betriebswirtschaftliche Forschung (ZbfF).

Jill R. Kickul is the Richard A. Forsythe Chair in Entrepreneurship in the Thomas C. Page Center for Entrepreneurship at Miami University (Ohio) and Professor in the Management Department in the Richard T. Farmer School of Business. Prior to joining the faculty of Miami University, she was the Elizabeth J. McCandless Professor in Entrepreneurship at the Simmons School of Management. Dr. Kickul's new book with Lisa Gundry, Entrepreneurship Strategy: Changing Patterns in New Venture Creation, Growth, and Reinvention, was released in August 2006. She was awarded the Cason Hall \& Company Publishers Best Paper Award as well as the Coleman Foundation Best Empirical Paper and the John Jack Award for Entrepreneurship Education. She has many publications in entrepreneurship and management journals, including Journal of Management, Journal of Small Business Management, Journal of Organizational Behavior, Frontiers of Entrepreneurship Research, International Journal of Entrepreneurship and Innovation, International Journal of Entrepreneurial Behavior and Research, and Academy of Management Learning and Education Journal. Finally, her work on entrepreneurship education development and curriculum design of the Simmons Certificate in Entrepreneurship has been nationally recognized and supported through the Coleman Foundation Entrepreneurship Excellence in Teaching Colleges Grant and has been named by Fortune Small Business as one of the Top 10 Innovative Programs in Entrepreneurship Education. 